\title{
Evaluating The Impact of Subsidies in Reducing Unemployment in Romania
}

\author{
Madalina Ecaterina POPESCU ${ }^{1}$, Maria Isadora LAZAR $^{2}$ and Andreea MURARU ${ }^{3}$ \\ ${ }^{1}$ The National Scientific Research Institute for Labor and Social Protection, Bucharest, Romania; \\ The Bucharest University of Economic Studies, Bucharest, Romania, \\ ${ }^{2,3}$ The Bucharest University of Economic Studies, Bucharest, Romania
}

Correspondence should be addressed to: Madalina Ecaterina POPESCU; madalina.andreica@gmail.com

Received date:23 September 2020; Accepted date: 25 January 2021; Published date: 6 July 2021

Academic Editor: Katalin Gál

Copyright (C) 2021. Madalina Ecaterina POPESCU, Maria Isadora LAZAR and Andreea MURARU. Distributed under Creative Commons Attribution 4.0 International CC-BY 4.0

\begin{abstract}
Having in mind the importance of effective Active Labour Market Policies (ALMPs) to boost employment, this paper aims to provide an impact study on employment for three types of active labour market measures implemented in Romania. These measures address companies who employ graduates of education institutions or unemployed persons over 45 years old or with only 3 years left before retirement. The impact of these measures was quantified one year and a half after the measures' conditionality ended, using survey data, counterfactual scenario and matching techniques. The findings of this study underline the utility of the active labour market measures regarding subsidies given to employers who employ graduates or unemployed persons over 45 years old and confirm the fact that this kind of programs have a positive effect on the short-run in encouraging employers to hire more graduates and persons over 45 years old.
\end{abstract}

Keywords: Active Labour Market Measure, Impact Assessment, Employment, Counterfactual Scenario

\section{Introduction}

High unemployment rates are a constant challenge for labour markets in many countries. Worldwide, unemployment rates are increasing, especially in some economic sectors, imposing significant pressure on public policies and causing severe effects in terms of social implications. Therefore, finding and applying appropriate policies

Cite this Article as: Madalina Ecaterina POPESCU, Maria Isadora LAZAR and Andreea MURARU (2021)," Evaluating The Impact of Subsidies in Reducing Unemployment in Romania", Journal of Eastern Europe Research in Business and Economics Vol. 2021 (2021), Article ID 866265, DOI: 10.5171/2021.866265 
to combat such phenomenon within a limited timeframe has become a priority for governments. One such policy tool to help prevent a drastic makeover of the labour market consists in designing and implementing effective Active Labour Market Policies (ALMPs) to reduce unemployment and boost employment in one country.

However, in order to properly design and implement such labour market measures, it is necessary to check their effectiveness, by conducting rigorous impact studies to assess the potential impact of such public policies upon the labour market. In case of a soon to be adopted policy, the assessment addresses its potential impact (ex-ante evaluation), while in case of an already implemented policy, the assessment focuses on the effects attributable to that policy (ex-post evaluation).

In order to evaluate the net impact of a specific ALMP (after excluding all other factors generating the outcome), counterfactual impact analysis is required. The counterfactual scenario underlying the evaluation aims to estimate what would have happened in the absence of the intervention. As the answer to this question is unknown, it is necessary to apply special statistical techniques. The basic idea of the method is to construct two groups of units similar in observable characteristics, with the only difference that those in the treatment group had access to the intervention, while the control group units did not receive that treatment. Thus, the difference between the measured results of the two groups of units will indicate the net impact of the intervention.

In this paper, the authors study the impact of three active labour market policies, consisting in subsidies granted to companies that employ graduates of education institutions or unemployed persons over 45 years old or with only 3 years left before retirement. The focus is on the impact of these measures upon employment on the labour market a year and a half after the completion of the measures and of their conditionality.
Empirical evidence for the case of the Romanian labour market is provided, using survey data.

In Romania, the LMPs were first introduced in 1991, having a real programme implemented only by the late 1990s. It consisted of both labour market services, passive and active labour market measures. Among them, labour market services mainly provide labour mediation, information and occupational counselling to facilitate labour market integration of job-seekers and unemployed persons.

On the other hand, passive measures aim to provide financial support (such as unemployment benefits, support allowance and allowance for vocational integration) to unemployed persons, job-seekers and early retired people. However, the benefits of the administration of unemployment can be rather difficult, especially in Romania, which is facing high informality with no reliable evidence of any wage payment for the rural population.

Finally, the ALMPs refer to those interventions in the labour market that aim to reduce unemployment by assisting people while shifting from inactivity to employment. There are several types of ALMPS:

- Measures dedicated to employ different types of disadvantaged categories of unemployed persons, such as: people over 45 , people with only 3 years left before retirement, graduates of educational institutions, etc. In these cases, employers receive subsidies for each unemployed person hired for a specific time horizon, under some strict predetermined conditions.

- Vocational training measures or labour mobility stimulation to increase employment opportunities.

- Small business assistance programmes to support start-ups and independent activities. These programmes provide counselling and assistance for developing the 
business plan and usually include forms of financial assistance.

For the purpose of this paper, the authors will only focus on the impact of the first type of ALMPs (aiming to employ graduates of education institutions or unemployed persons over 45 years old or with only 3 years left before retirement), on which the literature review is rather scarce.

According to Law no. 76/2002, article 85, employers who employ unemployed people over the age of 45 years for a minimum period of 18 months were entitled to benefit, for one year, of a monthly amount equal to the value of the social reference indicator for each person employed. When employing graduates of educational institutions, the companies were exempt from paying the contributions to the unemployment insurance budget for those graduates, while also receiving, for a period of one year, a monthly amount equal to:

(a) The value of the social reference indicator, at the time of employment, for graduates of lower secondary school or schools of arts and crafts;

(b) 1.2 times the value of the social reference indicator, at the time of employment, for graduates of higher secondary education or postsecondary education;

(c) 1.5 times the value of the social reference indicator, at the time of employment, for graduates of higher education.

The revised version of this law, that came into force on October 23rd 2013, no longer allows for the exemption from paying the contributions to the unemployment insurance fund. Instead, it keeps a simplified version of the provision referring to the monthly amount received by the employers for a period of 12 months (18 months for people with disabilities) that was then fixed at 900 Ron/month for all graduates, regardless of their education level.
In order to measure the impact of these measures upon employment in Romania, a counterfactual analysis was conducted using the Propensity Score Matching method (PSM). For this purpose, microdata was required. However, since the availability of such databases is rather scarce and no administrative datasets are open access to the academic and research environment in Romania, the authors made use of survey micro-data. The survey was conducted by the National Institute for Scientific Research in the Field of Labour and Social Protection (INCSMPS) in October 2014 among both the beneficiaries and non-beneficiaries of these measures. Even though the dataset might not accurately reflect the current economic context affected, for instance, by the COVID-19 pandemic, the authors accept such biases and pursue their aim of bringing empirically based evidences on the effects of subsidies addressed to employers of graduates or of unemployed persons over 45 years old. Since the current literature review on this topic is rather scarce, as the authors of this paper are unaware of any existing empirical study discussing the effectiveness of these particular types of measures, it is believed that this gap can be filled by investigating it and highlighting some particularities for the case of Romania.

The novelty of the paper is twofold. On one hand, it is relevant in terms of the methodological approach, as it brings insights on how to conduct such counterfactual impact assessment with limited access to administrative data. On the other hand, the authors share some insights on the effectiveness of such active labour market measures dedicated to employers in order to stimulate employment on the labour market. Even though the study can only provide insights upon the effectiveness of such measures for a single country case in a given period of time, it is believed that it adds value to the current labour market program evaluation literature, not only by providing some general conclusions on labor market policy implications, but also because such an assessment could be informative for policy design. 


\section{Literature Review}

Active labour market measures have been the center of attention for researchers, economists and decision makers due to the fact that high unemployment rates are problems that many European countries are facing and need to be tackled (Popescu and Lazar, 2015). Among those problems, a special focus must be directed to the young population, as the unemployment rates are higher for this age group and also because they are more vulnerable to demand-side risks, as demonstrated by the recent global financial crisis (Caliendo and Schmidl, 2016).

Previous research studies (Drăgoiu and Velciu, 2010; Militaru, 2015; Zamfir and Mocanu, 2016) underlined the fact that effective programs and investment in human resources can contribute to the economic recovery. In this respect, active labour market policies have proved to be an important tool in the fight against unemployment (Lehmann and Kluve, 2010; Pirciog et al., 2015; Popescu and Roman, 2018). Through an efficiency analysis, Roman (2008) proved the fact that active labour market measures are more efficient than passive ones.

Moreover, Kleuve (2010) showed that active labour market programs are widely used in European countries. Using a metaanalysis based on a data set of 137 program evaluations from 19 countries, the study concluded that it is almost exclusively the program type that seems to matter for program effectiveness. Blasco and Rosholm (2011) consider that the weak results concerning the effectiveness of some programs come from the fact that their positive outcomes are off-set by the low transition into employment during participation in programs (the "lock-in" effect). In their study on the effects of intensified ALMPs using data from an experiment in two Danish counties, they concluded that their effects are beyond the short-run, and that policy beneficiaries have greater average post-unemployment employment. Vooren et al. (2018) showed that some ALMPs (subsidized labour and public employment programs) have a negative impact on the short run, and this impact turns positive after 12 to 24 months of their implementation. Still, there are also studies like that of McKenzie (2017) that show that for developing countries, the positive impact expected by both policy makers and beneficiaries of active labour market policies is much higher than their effect and advocate for policies that help firms in creating jobs. Furthermore, there is also research, such as that of Wapler et al. (2018), on how ALMPs influence the regional market performance, showing that even though there is generally a positive effect, it is nevertheless dependent upon the conditions existent in the regional labour markets.

Therefore, the conclusions of the studies concerning the efficiency of ALMPs in different economies are mixed depending on the type of the policy applied, the time effect that is being investigated and also on the economy's characteristics, or as Pignatti and van Bell (2018) ${ }^{1}$ pointed out that there is very little evidence to show that policies that work well in one labour market context can be easily applied to another context.

The more recent study on ALMPs also investigates qualitative improvements in participants' lives. One such study is that of Dengler (2019) who investigates the impact of ALMPs on the job quality of welfare recipients in Germany, and concludes that participants in this type of programs succeed in having higher quality jobs than nonparticipants. The wellbeing of participants in ALMPs programs and the impact on their quality of life are inquired in a study developed on unemployed persons in Barcelona neighborhoods by Puig-Barrachina et al. (2020), where the authors reached the conclusion that these measures have positive effects on the

\footnotetext{
${ }^{1}$ These two authors study the interdependence between between active and passive labour market policies and stress the important effect of their interaction.
} 
wellbeing and mental health of participants.

Pervious empirical findings for the case of Romania indicate that ALMPs have, in general, positive effects on the labour market. For instance, Rodriguez-Planas and Jacob (2010) estimated the effects of four active labour market measures implemented in Romania in the late 1990's, using follow-up survey data and propensity score matching techniques. The results showed that training and retraining, selfemployment assistance and relocation services were beneficial in improving participants' incomes, while public employment was not. In 2015, Roman and Popescu (2015) estimated the effects of training on the Romanian migrants' income. By taking into consideration data of Romanian migrants worldwide, their research underlined that Romanian migrants had registered increased earnings after attending training at destination. In a more recent study, Popescu and Roman (2018) found that training measures in Romania have a positive, but modest impact upon employability in Romania. More precisely, participating in training programs increases employment chances by $15 \%$, being most successful for women and for people living in urban areas.

The impact assessment of active labour market measures on employment is still of high interest, due to the current economic context and the significant need of relevant public measures. This study is meant to provide insights on the impact upon employment a year and a half after the end of the implementation of three active labour market measures dedicated to stimulate employers to employ unemployed people.

The paper is organized as follows. The next section is dedicated to data description and the methodological approach, while the main findings are presented in section 3. The paper ends with some concluding remarks.

\section{Data Description and Methodology}

In order to evaluate the impact upon employment of the three active labour market measures dedicated to stimulate employers to employ unemployed people a year and a half after the completion of the measures, a quasi-experimental approach was applied. In order for the survey to be conducted, the National Agency of Employment (NAE) database was used to randomly select individuals that were registered as unemployed right before the implementation of these measures. The treatment groups were made up of a total sample of over 713 intervention beneficiaries, divided into three subsamples as presented in Table 1. A single control group was built to serve all three counterfactual scenarios. This control group consisted of 251 respondents who did not benefit from any of the three measures. Therefore, the difference between each treatment group and the control group consists in the fact that each treatment group benefitted from one of the three active labour market measures, while the control group did not.

Table 1: Sample sizes for each active labour market measure

\begin{tabular}{|l|c|c|}
\hline \multicolumn{1}{|c|}{ Active labour market measure } & \multicolumn{1}{|c|}{$\begin{array}{c}\text { Profile of the } \\
\text { beneficiaries }\end{array}$} & Sample size \\
\hline $\begin{array}{l}\text { Subsidies for employers who employ unemployed } \\
\text { persons over 45 years old }\end{array}$ & $\begin{array}{c}\text { urban males over 45, with } \\
\text { medium education level }\end{array}$ & $\begin{array}{c}154 \text { treated and } 251 \\
\text { non-participants }\end{array}$ \\
\hline $\begin{array}{l}\text { Subsidies for employers who employ unemployed } \\
\text { persons with only 3 years left before retirement }\end{array}$ & $\begin{array}{c}\text { urban males over 45, with } \\
\text { low education level }\end{array}$ & $\begin{array}{c}125 \text { treated and 251 } \\
\text { non-participants }\end{array}$ \\
\hline $\begin{array}{l}\text { Subsidies for employers who employ graduates of } \\
\text { education institutions }\end{array}$ & $\begin{array}{c}\text { young urban females, with } \\
\text { high education level }\end{array}$ & $\begin{array}{c}183 \text { treated and 247 } \\
\text { non-participants }\end{array}$ \\
\hline
\end{tabular}

Source: authors' own computation based on

survey data 
The Propensity Score Matching method (PSM) was applied distinctly for each labour measure using STATA 16 software. Probit models were first estimated to predict each individual's chances of receiving interventions through the public subsidies programs. In that respect, the authors built a binary treatment variable, which took value 1 in case of benefitting from a measure and 0 otherwise. Once the balancing property of the models was checked and the propensity scores of each individual were estimated, a nonparametric method for matching the treated units with the untreated ones was used based on the propensity scores.

The treatment and the control groups were matched, using a set of covariates that describe the relevant background information for each individual. In this set, both socio-demographic characteristics and economic variables were included. The authors chose the variables that were mentioned as relevant in previous empirical studies on this topic and also in accordance with the applicable economic theory. They considered the following covariates, taking into consideration the individual characteristics and coding them in different sub-categories, as follows:

a. Socio-demographic characteristics

- $\quad$ Age: between 15-24; between 2544; between 45-64; over 65;

- Gender: Male; Female;

- Residence area: Urban; Rural;

- Region: Bucharest-Ilfov; NorthEast; North-West; Centre; South; South-East; South-West; West;

- Level of education: Low level of education; Medium level of education; High level of education;

- Civil status: Married; Unmarried.

b. Economic variables

- Sector of activity: Services sector; Industry sector; Construction; Other sectors

- Years of work experience

The general form of the Probit model was:
Treatment $=f$ (age, gender, civil status, region, education level, residence, sector of activity, work experience)

Four matching algorithms were tested, namely: the Nearest Neighbour Matching Method, the Radius Matching Method, the Kernel Matching Method and the Stratification Method. The model allowed the authors to assess the ex-post impact of the active measures upon employment in Romania, by quantifying the odds of a participant to still be employed one year and a half after the end of the measures' conditionality, as compared to similar individuals in terms of observable characteristics, but who did not benefit from the measure.

\section{Main Findings}

The purpose of this paper was to determine the effects (if any) on the Romanian labour market of three types of subsidies dedicated to stimulate employers to employ unemployed people. In order to quantify the impact of these active labour market measures addressed to companies who employ graduates or unemployed persons over 45 years old or with only 3 years left before retirement, a propensity score matching technique was applied.

The results of the PSM technique that were statistically significant are summarized in Table 2, where the net impact was computed as the average treatment effect on the treated group (ATT). This estimator indicates the impact of the measures after computing the differences between the average outcomes of the two groups matched. The authors focused on the ATT of the ALMPs computed one year and a half after the measures' conditionality ended; however, for comparison reasons, the ATT was also computed right after the measures' conditionality ended.

The degree of satisfaction of the treated group upon the effectiveness of these public active measures was also quantified through a self-evaluation process. For that, the beneficiaries were asked to subjectively 
evaluate the impact of those active measures, considering their ability/inability to find a job in case of not benefitting from the measure.

Table 2: Impact of active labour market measures

\begin{tabular}{|l|c|c|c|}
\hline \multicolumn{1}{|c|}{$\begin{array}{c}\text { Active labour market } \\
\text { measure }\end{array}$} & $\begin{array}{c}\text { Self- } \\
\text { assessment } \\
\text { of the impact }\end{array}$ & $\begin{array}{c}\text { Net impact } \\
\text { when the } \\
\text { measure's } \\
\text { conditionality } \\
\text { ended }\end{array}$ & $\begin{array}{c}\text { Net impact one year } \\
\text { and a half after the } \\
\text { measure's } \\
\text { conditionality ended }\end{array}$ \\
\hline $\begin{array}{l}\text { Subsidies for employers who } \\
\text { employ unemployed persons } \\
\text { over 45 years old }\end{array}$ & $43 \%$ & $45 \%$ & $12 \%$ \\
\hline $\begin{array}{l}\text { Subsidies for employers who } \\
\text { employ unemployed persons } \\
\text { with only 3 years left before } \\
\text { retirement }\end{array}$ & $66 \%$ & $56 \%$ & $-18 \%$ \\
\hline $\begin{array}{l}\text { Subsidies for employers who } \\
\text { employ graduates of } \\
\text { education institutions }\end{array}$ & $25 \%$ & $34 \%$ & $16 \%$ \\
\hline
\end{tabular}

Source: authors' own computation based on survey data

In terms of self-assessment of the ALMPs impact, one can notice that all three public active measures were appreciated for their positive effects upon the chances of the unemployed persons to find a job. Among the three public active measures under discussion, the subsidies for the employers who employ unemployed persons with only 3 years left before retirement was the most appreciated one. Approximately, 66\% of the beneficiaries shared the opinion that they would not have found a job without this measure. The net impact computed right after the measure's conditionality ended was slightly lower (56\%, meaning that the beneficiaries of such ALMP actually had higher chances by $56 \%$ to get employed as compared to similar individuals right after the measures' conditionality ended). However, in terms of the net impact after one and a half year of the end of the measure's conditionality, the counterfactual impact assessment indicated a negative effect of the measure. More precisely, the findings suggest that the employment rate among the beneficiaries of this active measure was actually $18 \%$ lower compared to similar individuals who did not benefit from the measure. However, this negative impact must be interpreted with caution, because at the time the survey was conducted, $74 \%$ of the beneficiaries of the measure retired early, changing their status from employed to inactive.

When being asked to subjectively evaluate the impact of the measure providing subsidies for employers who employ unemployed persons over 45 years old, $43 \%$ of the beneficiaries shared the opinion that they would not have found a job without attending this program. Similar results were also obtained when computing the net effect right after the measure's conditionality ended (45\%). In terms of the net impact after one and a half year of the end of the measure's conditionality, the counterfactual analysis pointed out that the employment rate among the beneficiaries of this active measure was $12 \%$ higher compared to similar individuals who did not benefit from the measure. These findings indicate that the subsidies offered for employers who employ unemployed persons over 45 years old were rather effective in reaching the purpose to reduce the unemployment rate in Romania. Keeping in mind the fact that the unemployed persons over 45 years old were the most numerous among the sub-groups of beneficiaries of active labour market measures in Romania in that 
period, these results are rather relevant in terms of policy implications.

Regarding the graduates whose employers were subsidized, about three quarters were employed at the time the survey was conducted, that is 1 year and a half after the end of the employer's obligation to keep them employed. About $25 \%$ of the beneficiaries of the measure consider that they would not have found a job if they had not benefited from the intervention. Compared to the self-assessed impact of the measure, the counterfactual analysis indicated a slightly higher net impact right at the end of the measure's conditionality (of 34\%). However, in terms of sustainable results of the ALMPs, there is a lower level of the net impact one year and a half after the measure's conditionality ended. These findings are not surprising after all, considering that, in general, self-evaluation or investigation right after the measure ended might generate biased results. However, the statistical evaluation of the net impact suggests that the employment rate among the graduates who benefitted from this measure was $16 \%$ higher compared to similar graduates who did not benefit from the measure one year and a half after the measure's conditionality ended. This positive result is not surprising as wage subsidies are known to be a very good influencing factor among the ALMPs for youth, increasing their employment level in all circumstances, except in bad economic conditions, as shown by Caliendo and Schmidl (2016) in a study reviewing multiple evaluation studies in European countries.

Among the three public subsidies dedicated to stimulate employers to employ unemployed people, the findings suggest that the active measure dedicated to graduates of education institutions was slightly more effective in terms of the net impact upon employment in Romania. These findings could play an important role in public budgeting and in the labour market policy making process, as it brings insights regarding the effects upon employment that can be attributed to each active measure in particular.

Active policies are only some mechanisms among many others, such as unemployment insurance policies (passive policies), wage policies, policies concerning the safety of employment, policies on wage-setting mechanisms and policies concerning social dialogue. The lack of a correlation between all the objectives of these policies may cancel or mitigate the partial positive effects obtained. Given the multitude of possible factors that may influence the results of implementing some active measures, it is absolutely mandatory for any impact assessment to try to contextualize the best possible results.

Therefore, the authors decided to extend the impact analysis by breaking it down to socio-demographic characteristics (gender, residence area, level of education and age groups) in order to emphasize the effectiveness of each measure at the level of some specific sub-groups.

Several logit models were then estimated on each of the following sub-groups of individuals: male versus female, urban versus rural, low, medium and high level of education, distinct age groups (under 25; 25-45, over 45 years old). The output variable was the occupational status of the respondents, while the explanatory variables were the covariates: sex, age groups, marital status, levels of education, residence area and the "treatment" binary variable.

The valid econometric models were estimated in relation to LR test and pseudo $\mathrm{R}^{2}$ and also with statistically significant coefficients. A particular attention was paid to the significance of the "treatment" variable, which indicates the chances of a beneficiary of a certain measure to find a remunerated job at the time of the survey, compared to those of a non-beneficiary of the measure, with the same characteristics. The following conclusions were drawn from such sensitivity analysis, as presented in Table 3. 
Table 3: Degree of effectiveness of active labour market measures

\begin{tabular}{|l|l|}
\hline \multicolumn{1}{|c|}{ Active labour market measure } & \multicolumn{1}{c|}{ Degree of effectiveness of the measure } \\
\hline $\begin{array}{l}\text { Subsidies for employers who employ } \\
\text { unemployed persons over 45 years old }\end{array}$ & $\begin{array}{l}\text { Has a stronger effect on rural females over 45 } \\
\text { years old, with medium education level }\end{array}$ \\
\hline $\begin{array}{l}\text { Subsidies for employers who employ } \\
\text { unemployed persons with only 3 years left } \\
\text { before retirement }\end{array}$ & $\begin{array}{l}\text { Has a stronger effect, in general, on males over } \\
45 \text { years old. }\end{array}$ \\
\hline $\begin{array}{l}\text { Subsidies for employers who employ } \\
\text { graduates of education institutions }\end{array}$ & $\begin{array}{l}\text { Has a stronger effect on rural males with high } \\
\text { education level }\end{array}$ \\
\hline
\end{tabular}

\section{Conclusions}

The purpose of this paper consisted in estimating the impact of three active labour market measures in Romania, addressing companies who employ graduates of education institutions or unemployed persons over 45 years old or with only 3 years left before retirement. The authors focused on the impact of these measures on employment a year and a half after the completion of the measures and of their conditionality. In order to quantify the impact of these active labour market measures, a counterfactual impact assessment was applied using survey data and matching techniques.

Even though all three public active measures were subjectively appreciated for their positive effects on the chances to find a job, the authors bring empirical evidence to support the fact that the employment rates among the beneficiaries of at least two measures - those dedicated to graduates and to unemployed persons over 45 years old- were higher compared to similar non-treated individuals.

The findings of this research underline the utility of the active labour market measures concerning subsidies given to employers who employ graduates or unemployed persons over 45 years old and confirm the fact that this kind of programs have an effect on encouraging employers to hire more graduates and unemployed persons over 45 years old.

Among the three public subsidies, it was found that the active measure dedicated to graduates of education institutions was slightly more effective in terms of the net impact upon employment. In terms of gender differences, it is noticed that the active measures dedicated to graduates and to people who have 3 years left before retirement proved to be more effective among men, while the effects of the measure offering subsidies to companies which employ unemployed persons over 45 years old were more strongly noticed among women.

These findings could play an important role in public budgeting and in the labour market policy making process, as it brings insights regarding the effects upon employment that can be attributed to each active measure in particular. As policy recommendations aimed at increasing the efficiency and effectiveness of active labour market measures at the strategic level, the authors emphesize the need for conducting periodic assessments of the impact of active measures, as well as periodic studies and forecasts of the labour demand on short and medium terms.

Moreover, at the active labour market measure level, it is believed that better profiling of the persons looking for a job before being recommended for a certain measure could improve the outcomes of the program. Such impact evaluation studies, with findings similar to those that were briefly presented through this paper, could actually support the design of effective and evidence-based public policies. 


\section{Acknowledgments}

This work was supported by the NUCLEU Program funded by the Romanian Ministry of Research and Innovation (Project PN 19130103).

\section{References}

- Blasco. S., Rosholm, M. (2011), 'The Impact of Active Labour Market Policy on Post-Unemployment Outcomes: Evidence from a Social Experiment in Denmark', IZA Discussion Paper Series, 5631

- Caliendo, M., Schmidl, R. (2016), 'Youth unemployment and active labor market policies in Europe', IZA Journal of Labor Policy, 5(1).

- Dengler, K. (2019), 'Effectiveness of Active Labour Market Programmes on the Job Quality of Welfare Recipients in Germany', Journal of Social Policy, 48(4), 807-838. doi:10.1017/S0047279419000114.

- Drăgoiu, C. I., Velciu, M. (2010), 'Diverse and educated workforcerequirement in the recovery context',Annals of SpiruHaret University, 91.

- Kluve, J. (2010), 'The effectiveness of European active labour market programs',Labour economics, 17(6), 904-918.

- Lehmann, H., Kluve, J., (2010), 'Assessing Active Labour Market Policies in Transition Economies'. In: F. Caroleo F. and F. Pastore F., 'The Labour Market Impact of the EU Enlargement',AIEL Series in Labour Economics,Physica-Verlag HD.

- McKenzie, D., (2017), 'How Effective Are Active Labor Market Policies in Developing Countries? A Critical Review of Recent Evidence', World Bank Policy Research Working Paper, 8011.

- Militaru, E. (2015), 'The redistributive effect of the Romanian tax-benefit system: A microsimulation approach', Journal of Applied Quantitative Methods, 10(1).

- Pignatti, C., van Belle, E. (2018), 'Better together: Active and passive labour market policies in developed and developing economies', ILO Working Paper, 37.

- Pirciog, S., Ciuca, V. and Popescu, M.E. (2015), 'The net impact of training measures from active labour market programs in Romania - subjective and objective evaluation', Procedia Economics and Finance, 26, 339-344.

- Popescu, M.E. and Roman, M. (2018), 'Vocational training and employability: Evaluation evidence from Romania', Evaluation and Program Planning, 67, 3846,https://doi.org/10.1016/i.evalpro gplan.2017.11.001

- Popescu, M.E., Lazar, M.I. (2015), 'Analysis of the post-crisis economic performances in the European Union', ActaUniversitatisDanubius.

OEconomica, 11(3), 5-14.

- Puig-Barrachina, V., Malmusi, D., Artazcoz, L. et al. (2020), 'How does a targeted active labour market program impact on the well-being of the unemployed? A concept mapping study on Barcelona "Employment in the Neighbourhoods"', BMC Public Health 20, 345https://doi.org/10.1186/s12889020-8441-2.

- Rodriguez-Planas, N., Jacob, B. (2010), 'Evaluating active labour market programs in Romania',Empirical Economics, 38(1), 65-84.

- Roman, M. (2008), 'The efficiency analysis applied for the evaluation of labour market policies: Study case for Romania', MPRA, 20332, Available: http://mpra.ub.uni-muenchen.de/

- Roman, M., Popescu, M.E., (2015), 'The Effects of Training on Romanian Migrants' Income: A Propensity Score Matching Approach', Economic Computation and Economic Cybernetics Studies and Research, 1(43), 85-108.

- Vooren, M., Haelermans, C., Groot W., van den Brink H. (2019), 'The Effectiveness of active labor market policies: a meta-analysis', Journal of Economic Surveys, 33(1), 125-140.

- Wapler, R., Wolf, K., Wolff, J., (2018), 'Do active labour market policies for welfare recipients in Germany raise their regional outflow intowork? A 
matching function approach', IABDiscussion Paper, No. 8.

- Zamfir, A.M. and Mocanu, C. (2016), 'Human capital, inequalities and labour market participation in Romania', SEA-Practical Application of Science, 4(1), 135-140. 